Published in final edited form as:

Account Res. 2019 April ; 26(3): 246-251. doi:10.1080/08989621.2019.1585819.

\title{
Stewardship of Research Resources
}

\author{
David B. Resnik, JD, PhD [Bioethicist and IRB Chair] \\ National Institute for Environmental Health Sciences, National Institutes of Health, 111 Alexander \\ Drive, Box 12233, Mail Drop E1-06, Research Triangle Park, NC, 27709 USA, \\ resnikd@niehs.nih.gov, Phone, Office: 9842874208 Cell: 9193702702
}

\section{Stewardship of Research Resources}

Most accounts of research ethics focus on the importance of a handful of ethical and epistemological norms for the conduct of science, such as honesty, integrity, transparency, accountability, objectivity, collegiality, fairness, social responsibility (Steneck 2006, Macrina 2013, Stewart 2011, Briggle and Mitcham 2012, Comstock 2012), but have little to say about another, less well-known norm, that also deserves attention: stewardship of research resources. Many of the behaviors and practices that are widely regarded as unethical or ethically questionable involve wasting or misusing money, time, and other resources (Shamoo and Resnik 2105).

Consider, for example, the case of German anesthesiologist Joachim Boldt, who was found to have fabricated and falsified data pertaining to dozens of clinical studies from 1999 to 2010. In May 2010, a German medical association, Landesärztekammer Rheinland-Pfalz (LAKRLP), began investigating Boldt after readers of the journal Anesthesia and Analgesia questioned the authenticity of the data in an article he had published in December 2009 (Wise 2013). Although LAKRLP did not have the authority to examine the scientific validity of Boldt's research, it did find in that he had not obtained ethical approval for the study and that patients had not signed a consent document. Shortly thereafter, Anesthesia and Analgesia found that Boldt had fabricated and falsified data for the study, and it retracted the article in October 2010 (Wise 2013). In November, the hospital where Boldt worked, Klinikum Ludwigshafen, began investigating Boldt and found that he had fabricated or falsified data in numerous studies dating back to 1999. The hospital terminated Boldt's contract. In February 2011, LAKRLP announced that as many as 90 articles Boldt had published may need to be retracted because he had not obtained ethical approval for the research. In March 2011, the editors of eighteen medical journals published a statement announcing their plans to retract 88 of Boldt's articles. Many of Boldt's fraudulent studies had purported to demonstrate the relative benefits of using hydroxyethyl starch in fluid resuscitation, as compared to other types of fluids. In February 2013, a meta-analysis that excluded Boldt's studies, published in the Journal of the American Medical Association, found that hydroxyethyl starch was associated with an increased risk of death and acute kidney injury, as compared to other fluids used in resuscitation (Wise 2013).

There are many reasons why we should regard Boldt's ethical transgressions as particularly egregious: they undermined the integrity of the research record, placed thousands of patients at risk, and violated rules for protecting human subjects. But one thing we should not forget 
to add to this list is that Boldt's misconduct wasted a tremendous amount of time, effort, money, and other resources. This agglomeration of waste includes: the time and effort of collaborators and research staff, who helped conduct his studies; the time and effort of patients who participated in his studies; the time and effort of editors and reviewers who reviewed his articles; the time and effort of the editors who investigated his research and retracted his articles; the time and effort of institutional committee members who investigated his research; the time and effort of researchers who read Boldt's articles and mistakenly relied upon his data and results; the money that sponsors provided for Boldt's research; and the resources that the hospital provided to Boldt (e.g. space, equipment, materials, supplies, administrative support, etc.).

What does it mean to be a good steward of research resources? A steward is a person who is responsible for taking care of someone else's resources. The first duty of stewardship is to ensure that resources are used efficiently. For example, duplicate publication, i.e. publishing the same data or results in another journal, is an inefficient use of resources because it wastes the time and effort of reviewers and editors. The second duty is to ensure that resources are used appropriately. Resources should be used to achieve their intended goals. For example, diverting grant funds to pay for research, food, or travel not covered by the grant is using resources inappropriately.

Besides data fabrication and falsification, other unethical or ethically questionable research practices that involve waste or misuse of resources include:

- $\quad$ Poorly designed studies waste funding provided by sponsors; institutional resources; and the time of research staff, students, journal editors and reviewers, and human subjects (in some cases).

- Irreproducible research wastes funding provided by the sponsor; institutional resources; and the time of research staff, students, journal editor and reviewers, human subjects (in some cases), and other scientists who rely on the research or attempt to reproduce it.

- Redundant research wastes resources on topics or questions that have already adequately addressed in the published literature.

- Carelessness in science includes various activities that waste resources, such as misusing or breaking equipment; misplacing, mislabeling, or mishandling records, data or materials; and poor record-keeping.

- "Salami science," e.g. dividing papers into small units to maximize the total number of publications, wastes the time of journal editors and reviewers and other scientists who piece together data and results published in different venues to understanding the research.

- Unethical research involving communities may give members of these groups and negative impression of science and dissuade them from participating in future research studies, thereby preventing other researchers from studying them.

- Improper excavation of archeological sites or fossil remains may disturb or ruin the material such that it is useless to other researchers. 
- $\quad$ Bullying and harassment can induce fear, anxiety, stress, anger, and other reactions in victims that undermine the efficiency of research and can cause some to leave science for other careers, which wastes the investment in their scientific education.

Admittedly, many of the misbehaviors described above involve violations of norms other than stewardship of resources. For example, data fabrication and falsification are forms of dishonesty, and most researchers would regard these behaviors as highly unethical even if they did not waste money, resources, or time. Bullying and harassment would also be regarded as wrong even if these misbehaviors did not waste resources, because they violate the rights, dignity, and wellbeing of victims. It should come as no surprise, however, that conduct widely regarded as unethical or ethically questionable violates more than one norm, given the complexity or human behavior and our moral intuitions. For example, plagiarism is regarded as wrong because it involves the theft of intellectual property (i.e. the stealing words, data, or ideas) and it dishonestly represents the authorship of creative works (Shamoo and Resnik 2015). However, in some situations, such as "salami science," careless research, and improper excavation, poor stewardship of resources is the primary ethical concern.

Stewardship of resources may seem like a rather mundane ethical principle, but it is important in research for several reasons. First, misuse of resources often wastes public money. Public money may support research directly (e.g. through grants or contracts) or indirectly (e.g. via the utilization of publicly owned buildings, materials, or equipment). Wasting public money is unethical because it violates the public's trust and undermines the public's support for research (Shamoo and Resnik 2015). Imprudent use of private research funding is also unethical because it also violates the trust that private sponsors place in researchers. Second, misuse use of resources often wastes time and effort, which are precious commodities in science. Most scientists work long hours and must divide their time and effort between research, teaching, mentoring, administrative responsibilities, and reviewing for manuscripts submitted for publication or research proposals submitted to sponsors. Scientists - and other people involved in research, such as technicians or students - can ill-afford to spend their time and effort on unnecessary or futile tasks. Third, by wasting someone else's time and effort, misuse of resources shows a lack of respect for that person. Someone who is always late for his or her appointments shows a lack of concern for the interests of people who are waiting for him or her to show up. The chronically tardy person is saying, in effect, "your time is not very important to me." The same point holds when a researcher wastes the time of a colleague, graduate student, technician, reviewer, or editor.

Stewardship may sometimes conflict with other ethical principles. For example, many of the ethical requirements that protect the rights and welfare of human research subjects can also interfere with the efficiency of research (Resnik 2018). To protect privacy and confidentiality of human research subjects it may be necessary to require researchers to sign data use agreements as a condition of receiving de-identified genomic data. Data use agreements typically obligate researchers to not to identify individuals or share data without permission (Resnik 2010). Imposing this requirement on data sharing commits resources (e.g. time, effort, money) to administrative tasks that could be used to support research instead. A more 
efficient way to share genomic data would be to make it publicly available on a website, but this method could threaten privacy and confidentiality, in some cases (Resnik 2010).

Likewise, ethical rules that protect the welfare of laboratory animals may also interfere with efficiency. For example, analgesia medications cost money and may interfere with experimental results in some cases, but they often are necessary to minimize animal pain and suffering (Shamoo and Resnik 2015). Thus, stewardship of resources, like other research norms, must be balanced against other ethical considerations, such as protection of human and animal subjects, which may take precedence in some situations.

Decisions concerning the use of government funds to support research also raise questions concerning stewardship since the public expects and deserves a reasonable return on its investment. Scientists who make decisions concerning the allocation of government funds or serve on panels that evaluate research proposals should take into consideration issues related to the efficient use of resources. While most people would agree that public money should not be wasted on research that is unlikely to have a significant impact on science or society, determining the potential impact of proposed projects can be difficult, especially when they do not have an immediate, tangible impact. Debates often arise concerning the allocation of funds to basic vs. applied sciences, natural sciences vs. social sciences, and big science projects (such as the Human Genome Project, the Hubble telescope) vs., smaller ones (Resnik 2009).

While good stewardship of resources may not be as crucial to the ethics of science as other norms, such as honesty, transparency, and accountability, it is an important consideration that scientists should keep in mind when managing their own resources or mentoring students and trainees in the responsible conduct of research. Additional investigation into the ethics of stewardship may help us better understand how this norm interacts with other research norms and guides scientific conduct.

\section{Acknowledgments}

This research was supported by the Intramural Program of the National Institute of Environmental Health Sciences (NIEHS), National Institutes of Health (NIH). It does not represent the views of the NIEHS, NIH, or US government.

\section{References}

Briggle A, Mitcham C. 2012 Ethics and Science: An Introduction. Cambridge, UK: Cambridge University Press.

Comstock G 2012 Research Ethics: A Philosophical Guide to the Responsible Conduct of Research. Cambridge, UK: Cambridge University Press.

Marcina F (ed.). 2013 Scientific Integrity, 4th ed. Washington, DC: American Society for Microbiology Press.

Resnik DB. 2009 Playing Politics with Science: Balancing Scientific Independence and Government Oversight. New York: Oxford University Press.

Resnik DB. 2010 Genomic research data: open vs. restricted access. IRB 32(1): 1-6.

Resnik DB. 2018 The Ethics of Research with Human Subjects: Protecting People, Advancing Science, Promoting Trust. Cham, Switzerland: Springer.

Shamoo AE, Resnik DB. 2015 Responsible Conduct of Research, 3rd ed. New York, NY: Oxford University Press. 
Steneck N 2006 ORI Introduction to the Responsible Conduct of Research. Washington, DC: Office of Research Integrity.

Stewart N 2011 Research Ethics for Scientists. New York, NY: Wiley-Blackwell.

Wise J 2013 Boldt: the great Pretender. British Medical Journal 346:16-18. 